\title{
Erratum to: Efficacy of Different Disinfectant Systems on Alginate and Addition Silicone Impression Materials of Indian and International Origin: A Comparative Evaluation
}

\author{
R. K. Samra $\cdot$ S. V. Bhide
}

Published online: 4 December 2011

(C) Indian Prosthodontic Society 2011

Erratum to: J Indian Prosthodont Soc (2010)

10(3):182-189

DOI 10.1007/s13191-010-0040-y

In the original publication of the article, Fig. 2 was published incorrectly and the error is deeply regretted by the authors. The correct version of Fig. 2 is provided here.

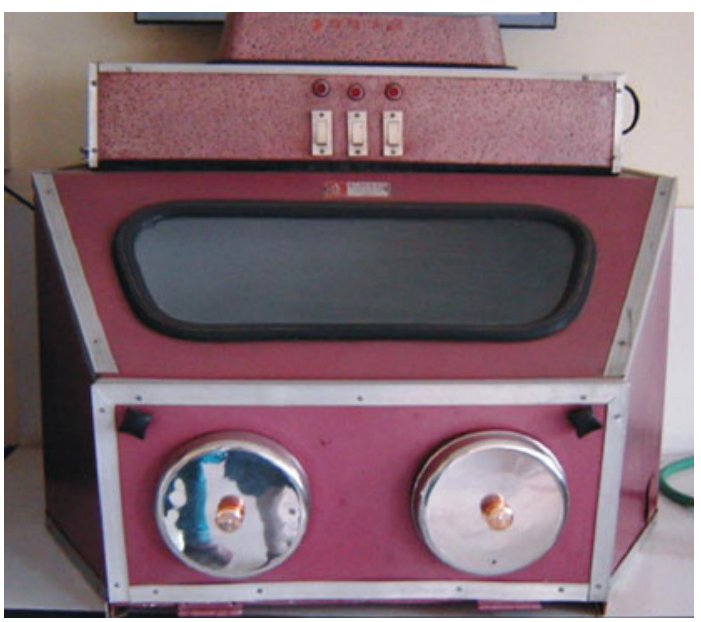

Fig. 2 UV light disinfection unit

The online version of the original article can be found under doi:10.1007/s13191-010-0040-y.

R. K. Samra · S. V. Bhide

Department of Prosthodontics, Bharati Vidyapeeth Dental

College \& Hospital, Katraj, Dhanakawadi, Pune, India

R. K. Samra $(\bowtie)$

Department of Prosthodontics, Gian Sagar Dental College

\& Hospital, Rajpura, Patiala 147001, India

e-mail: rupansamra15@rediffmail.com

R. K. Samra

House No. 10, Doctor's Colony, Bhadson Road,

Patiala 147001, India 